\title{
pesquisa
}

SILVA, J.R.V.; COSTA, N.V.; MORAIS, O.S.; TERRA, M.A.; MARCHI, S.R.; ONO, E.O. Brotação de mini-tubérculos de sete cultivares de batata em função de concentrações de bissulfureto de carbono. Horticultura Brasileira, Brasília, v.22, n.4, p.677-680, out-dez 2004.

\section{Brotação de mini-tubérculos de sete cultivares de batata em função de concentrações de bissulfureto de carbono}

\author{
João Renato V. da Silva ${ }^{1}$; Neumárcio V. da Costa $^{1}$; Otávio S. Morais ${ }^{1}$; Marcelo A. Terra ${ }^{1}$; Sidnei Roberto \\ de Marchi' ${ }^{1}$; Elizabeth Orika Ono ${ }^{2}$ \\ UNESP, FCA, C. postal 237, 18603-970 Botucatu-SP; E-mail:jrvsilva@ fca.unesp.br; ${ }^{1}$ Aluno pós-graduação
}

\section{RESUMO}

Estudou-se o efeito de concentrações de bissulfureto de carbono sobre a brotação de mini-tubérculos de batata. O ensaio foi instalado no esquema fatorial $5 \times 7$, onde as variáveis constaram de quatro diferentes doses de bissulfureto de carbono (10; 20; 30 e $\left.40 \mathrm{mg} \mathrm{L}^{-1}\right)$ além do controle e sete cultivares de batata (Bintje, Jaete Bintje, Atlantic, Cupido, Ágata, Monalisa e Mondial). Os tratamentos com bissulfureto de carbono foram aplicados durante um período de 72 horas, após o qual os mini-tubérculos de batata foram colocados em bandejas de isopor para brotação. De forma geral, todas as concentrações de bissulfureto de carbono estimularam a brotação. As cultivares Bintje e Atlantic responderam de forma positiva ao bissulfureto de carbono, onde o aumento da concentração levou ao aumento do número de brotos por tubérculo. As cultivares Ágata e Mondial responderam positivamente à concentração de $10 \mathrm{mg} \mathrm{L}^{-1}$, sendo que o acréscimo nas concentrações pouco interferiu no número de brotos por tubérculo. As cultivares Jaete Bintje e Monalisa só responderam às concentrações de $20 \mathrm{e} 30 \mathrm{mg} \mathrm{L}^{-1}$, e na de $40 \mathrm{mg} \mathrm{L}^{-1}$ o bissulfureto de carbono provocou a queima de gemas.

Palavras-chave: Solanum tuberosum, batata-semente, dormência, dominância apical.

\begin{abstract}
Effects of carbon bisulfide on sprouting of potato mini-tubers

Concentrations of carbon bisulfide on sprouting of potato mini tubers was evaluated. The study was set as a factorial experiment. The treatments were composed of four concentrations of carbon bisulfide (10; 20; 30 and $\left.40 \mathrm{mg} \mathrm{L}^{-1}\right)$ besides the control and seven potato cultivars (Bintje, Jaete Bintje, Atlantic, Cupido, Agata, Monalisa and Mondial). The potato mini-tubers were treated with carbon bisulfide during 72 hours in a closed recipient and then allowed to sprout. All concentrations of carbon bisulfide enabled the potato sprouting. Bintje and Atlantic tubers increased sprouting under higher carbon bisulfide concentrations. Tuber sprouting of Agata and Mondial did no respond to carbon bisulfide concentrations over $10 \mathrm{mg} \mathrm{L}^{-1}$. Jaete Bintje and Monalisa presented the best results when 20 and $30 \mathrm{mg} \mathrm{L}^{-1}$ of carbon bisulfide was used.
\end{abstract}

Keywords: Solanum tuberosum, potato seed, dormancy, apical dominance.

(Recebido para publicação em 14 de outubro de 2003 e aceito em 2 de setembro de 2004)

A batata (Solanum tuberosum L.) é normalmente propagada vegetativamente, por meio do plantio de tubérculos-semente. Estes, ao contrário das sementes botânicas, nunca estão realmente em repouso absoluto, sofrendo uma série constante de modificações bioquímicas, desde o início da tuberização até o início da brotação.

Um dos fatores de produção mais importantes para a cultura, é o estado fisiológico dos tubérculos-semente e o correspondente desenvolvimento da brotação no ato do plantio. Nas condições brasileiras, onde o ciclo da cultura é bastante curto, estes fatores devem, obrigatoriamente, promover rápida e uniforme emergência das plantas, para alcançar o máximo desenvolvimento vegetativo, no menor período de tempo. Para isto, os tubérculos devem apre- sentar brotos curtos, vigorosos e capazes de proporcionar rápido desenvolvimento vegetativo da cultura, em condições de solo adequado (Castro, 1976).

O termo dormência é, usualmente, utilizado em qualquer estádio do ciclo de desenvolvimento das plantas e pode referir-se a sementes, gemas florais, rizomas, bulbos e tubérculos (Toledo e Marcos Filho, 1977). Em tubérculos de batata, as gemas permanecem inaptas à brotação durante certo período, mesmo sob condições adequadas ao seu crescimento. Para alguns pesquisadores, esse estádio, resultante de causas endógenas, é denominado de período de repouso. Terminada essa fase, as gemas podem ainda não iniciar a brotação se as condições ambientais, principalmente temperatura, forem desfavoráveis. Esse estádio é chamado de quiescência.
Dormência é então, considerada neste trabalho, como o período total durante o qual as gemas estão inaptas a brotar, como resultado de causas endógenas e exógenas. O período de dormência depende da própria cultivar, das condições climáticas durante o desenvolvimento da cultura, do grau de maturação dos tubérculos, de injúrias mecânicas, de doenças e danos causados por insetos nos tubérculos. O mecanismo de dormência pode ser visto como uma defesa natural da espécie, uma vez que é governada por fatores específicos que regulam ou paralisam o desenvolvimento dos órgãos até que as condições sejam favoráveis.

A ativação da brotação é um recurso que vem, desde há muito tempo, sendo utilizado pelos bataticultores a fim de uniformizar a brotação. Várias são 
Tabela 1. Número de brotos por tubérculo, submetidos a diferentes concentrações de bissulfureto de carbono $\left(\mathrm{CS}_{2}\right)$, em diferentes cultivares de batata, avaliados aos 35 dias após o tratamento. Botucatu, UNESP, 2002.

\begin{tabular}{|c|c|c|c|c|c|c|c|}
\hline \multirow{2}{*}{$\begin{array}{l}\text { Concentração } \\
\left(\mathrm{mg} \mathrm{L}^{-1}\right) \text { de } \mathrm{CS}_{2}\end{array}$} & \multicolumn{7}{|c|}{ Cultivares $^{1}$} \\
\hline & Bintje & Jaete Bintje & Atlantic & Cupido & Ágata & Monalisa & Mondial \\
\hline 0 & $0,71 \mathrm{Ab}^{*}$ & $0,71 \mathrm{Ac}$ & $0,71 \mathrm{Ab}$ & $0,71 \mathrm{Ab}$ & $0,71 \mathrm{Ac}$ & $0,74 \mathrm{Ab}$ & $1,02 \mathrm{Ab}$ \\
\hline 10 & $1,13 \mathrm{Cb}$ & $0,71 \mathrm{Cc}$ & $0,87 \mathrm{Cb}$ & $0,94 \mathrm{Cb}$ & $1,91 \mathrm{Bb}$ & $0,79 \mathrm{Cb}$ & 2,39Aa \\
\hline 20 & $1,73 \mathrm{Ba}$ & $2,05 \mathrm{ABab}$ & 1,22Cab & $1,64 \mathrm{BCa}$ & $1,77 \mathrm{Bb}$ & $1,21 \mathrm{Cb}$ & 2,31Aa \\
\hline 30 & $2,15 \mathrm{ABa}$ & $2,45 \mathrm{Aa}$ & $1,54 \mathrm{Ca}$ & $1,77 \mathrm{BCa}$ & $2,46 \mathrm{Aa}$ & $2,10 \mathrm{ABa}$ & $2,14 \mathrm{ABa}$ \\
\hline 40 & $2,23 \mathrm{ABa}$ & $1,64 \mathrm{CDb}$ & 1,48DEa & 1,91BCDa & 2,00ABCab & 1,01Eb & $2,43 \mathrm{Aa}$ \\
\hline $\begin{array}{l}\text { FDose (D) } \\
\text { FCultivar (C) } \\
\text { FD x C }\end{array}$ & $\begin{array}{r}259,58^{* *} \\
68,53^{* *} \\
13,49^{* *}\end{array}$ & & & & & & \\
\hline C.V. (\%) & 11,31 & & & & & & \\
\hline
\end{tabular}

1 Dados transformados em " $(\mathrm{x}+0,5)$.

* Médias seguidas de mesma letra maiúscula na linha, e minúscula na coluna, não diferem estatisticamente entre si pelo teste Tukey, ao nível de $5 \%$ de probabilidade.

as técnicas empregadas para a quebra da dormência como, por exemplo, corte dos tubérculos, choques térmicos, abafamentos e uso de substâncias químicas.

Dentre os compostos químicos, o bissulfureto de carbono é uma substância líquida, de evaporação rápida e que possibilita certa antecipação no plantio dos tubérculos, numa correlação positiva entre o número de hastes, produção de tubérculos e emergência mais rápida de plantas (Scivittaro e Boock, 1963; Meijers, 1972; Daniels, 1980). Embora apresente certa eficiência na quebra de dormência de gemas de tubérculos de batata, em alguns casos e em função da dose, do tempo de tratamento e da sensibilidade da cultivar, o bissulfureto de carbono pode também apresentar alguns inconvenientes como alongamento de hastes, atraso na tuberização, mudanças no formato dos tubérculos (Timm et al. 1962), brotação insuficiente ou queima de brotos.

O presente trabalho teve por objetivo avaliar o efeito de quatro concentrações de bissulfureto de carbono sobre a brotação de mini-tubérculos provenientes de sete cultivares de batata.

\section{MATERIAL E MÉTODOS}

O presente trabalho foi instalado na UNESP em Botucatu (SP), no ano de 2002. O delineamento experimental utilizado foi inteiramente casualizado em esquema fatorial $5 \times 7$, com quatro concentrações de bissulfureto de carbono
95\% (10; 20; 30 e $\left.40 \mathrm{mg} \mathrm{L}^{-1}\right)$ e controle visando à indução do brotamento de mini-tubérculos de sete cultivares de batata (Bintje, Jaete Bintje, Atlantic, Cupido, Ágata, Monalisa e Mondial). As unidades experimentais foram constituídas de cinco mini-tubérculos de cada cultivar, num total de quatro repetições.

A indução da brotação procedeu-se utilizando recipientes plásticos com capacidade de vinte litros, nos quais foram devidamente acondicionados os mini-tubérculos de batata. O produto, em sua forma líquida, foi dosado na concentração desejada com o auxílio de uma micro-pipeta e colocado sobre placas de Petri evitando-se assim o contato direto com os mini-tubérculos e possíveis danos a estes. Imediatamente após a deposição do bissulfureto de carbono nas placas de Petri, todos os recipientes plásticos foram hermeticamente fechados e lacrados com fita vedante, evitando-se assim perdas do gás de bissulfureto de carbono por difusão no ambiente. O tempo de exposição dos mini-tubérculos ao bissulfureto de carbono foi de 72 horas e, após esse período, os recipientes plásticos foram abertos e os mini-tubérculos retirados, dispostos em bandejas de isopor (14 $\mathrm{x}$ $21 \mathrm{~cm}$ ) e colocados sobre bancadas à sombra e temperatura ambiente. Durante o período de observação da brotação, a temperatura média diária esteve entre o mínimo de $15^{\circ} \mathrm{C}$ e o máximo de $26^{\circ} \mathrm{C}$.

A possível influência das diferentes concentrações de bissulfureto de carbono foi mensurada por meio do número de brotos visíveis por mini-tubérculo aos 35 dias após o tratamento (DAT), sendo que após este período, o número de brotos por mini-tubérculo permaneceu constante em todos os tratamentos. Os resultados foram submetidos à analise de variância (teste $\mathrm{F}$ ) e análise de regressão, sendo as médias comparadas pelo teste Tukey a 5\% de probabilidade.

\section{RESULTADOS E DISCUSSÃO}

Aos 35 dias após o tratamento (DAT) não foi mais observado incremento de brotação em relação à avaliação anterior. Houve efeito das concentrações de bissulfureto de carbono na quebra de dormência dos mini-tubérculos de batata (Tabela 1). As concentrações de bissulfureto de carbono estimularam a brotação dos tubérculos de batata, porém a dose de $10 \mathrm{mg} \mathrm{L}^{-1}$ diferiu significativamente da testemunha apenas para a cultivar Ágata e Mondial. Este tipo de resposta em relação ao aumento da dose, já era esperado uma vez que já são conhecidos os efeitos das substâncias químicas utilizadas para a quebra de dormência de tubérculos de batata (Daniels, 1980; Reghin, 1982; Pógi e Brinholi, 1995).

Um dos pontos fundamentais no sucesso da utilização dessa substância é a penetração do composto no tubérculo, uma vez que os tubérculos estão dormentes, com a taxa de atividade metabólica e respiratória muito baixa. Com isso, as trocas gasosas entre o tubérculo e o meio ficam reduzidas a quase zero, 
o que impede a difusão ou entrada do bissulfureto de carbono no interior do tubérculo. Deste modo, a eficiência do produto só é conseguida em pedaços cortados ou em tubérculos com a película danificada (Beukma e Zaag, 1979). Porém, nota-se que tal fato não ocorreu neste ensaio, comprovando que o tempo de contato do produto com os tubérculos, é também capaz de auxiliar na eficiência, aumentando a penetração do produto e, proporcionando uma boa brotação das sementes de batata.

Verificou-se efeito significativo do bissulfureto de carbono sobre as cultivares de batata, as quais apresentaram comportamento diferenciado frente às concentrações, mesmo aquelas cultivares consideradas de difícil brotação (Atlantic e Cupido). Pógi e Brinholi (1993), estudando o efeito do ácido giberélico e do bissulfureto de carbono sobre a quebra de dormência de tubérculos de batata, verificaram que a concentração e/ou o tempo de aplicação do produto podem proporcionar estímulos diferenciados nas diferentes cultivares de batata.

As cultivares Bintje, Atlantic e Cupido, em relação às diferentes concentrações de bissulfureto de carbono, avaliados aos 35 DAT, apresentaram regressão linear (Figura 1). É possível verificar que as três cultivares mostraram comportamento semelhante, sendo que para a concentração de $10 \mathrm{mg} \mathrm{L}^{-1}$, não houve diferença significativa em relação à testemunha para brotação dos mini-tubérculos. O número médio de brotos por mini-tubérculo aumentou à medida que houve acréscimo na concentração do bissulfureto de carbono, revelando que as concentrações utilizadas não causaram problemas de fitotoxicidade e, conseqüente, queima das gemas.

Comportamento diferenciado foi verificado nas cultivares Jaete Bintje e Monalisa. Nota-se que $10 \mathrm{mg} \mathrm{L}^{-1}$ de bissulfureto de carbono estimulou muito pouco a brotação dos mini-tubérculos aos 35 DAT, sendo que o número médio de brotos por tubérculo foi, praticamente, igual à testemunha não tratada (Figura 2). Os dados obtidos para essas cultivares ajustaram-se a uma função cúbica. Os melhores resultados re-

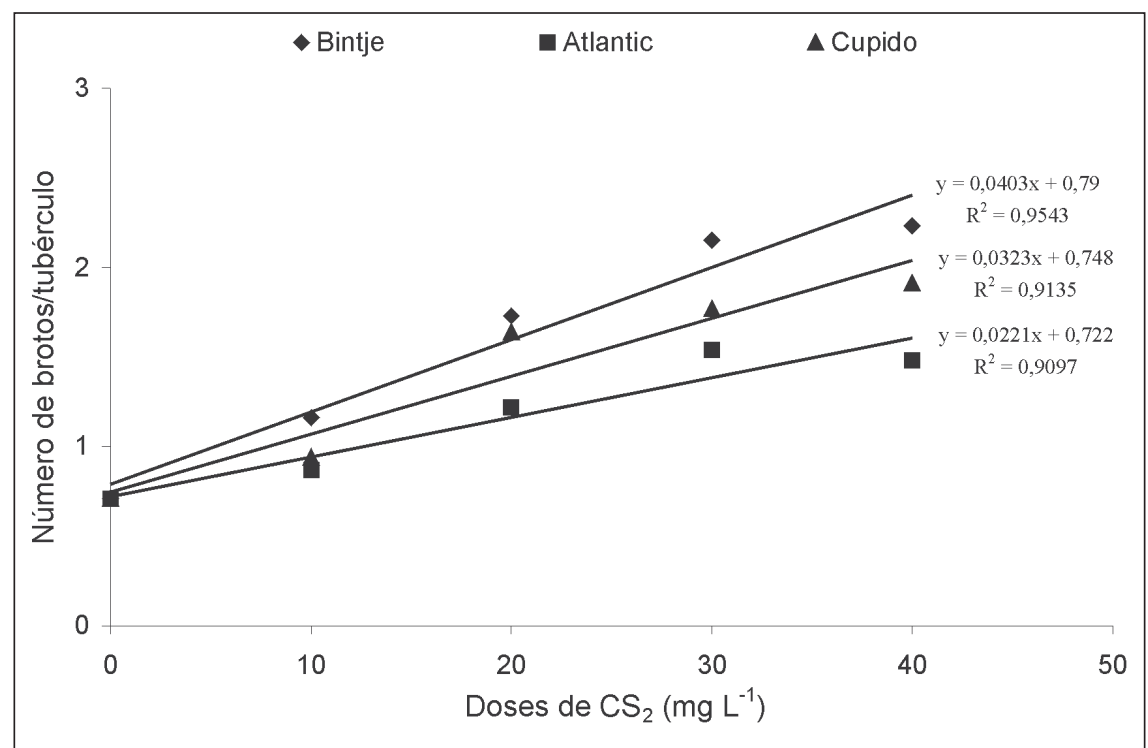

Figura 1. Comportamento da brotação de mini-tubérculos de batata das cultivares Bintje, Atlantic e Cupido em relação às diferentes concentrações de $\mathrm{CS}_{2}$, aos 35 DAT. Botucatu, UNESP, 2002.

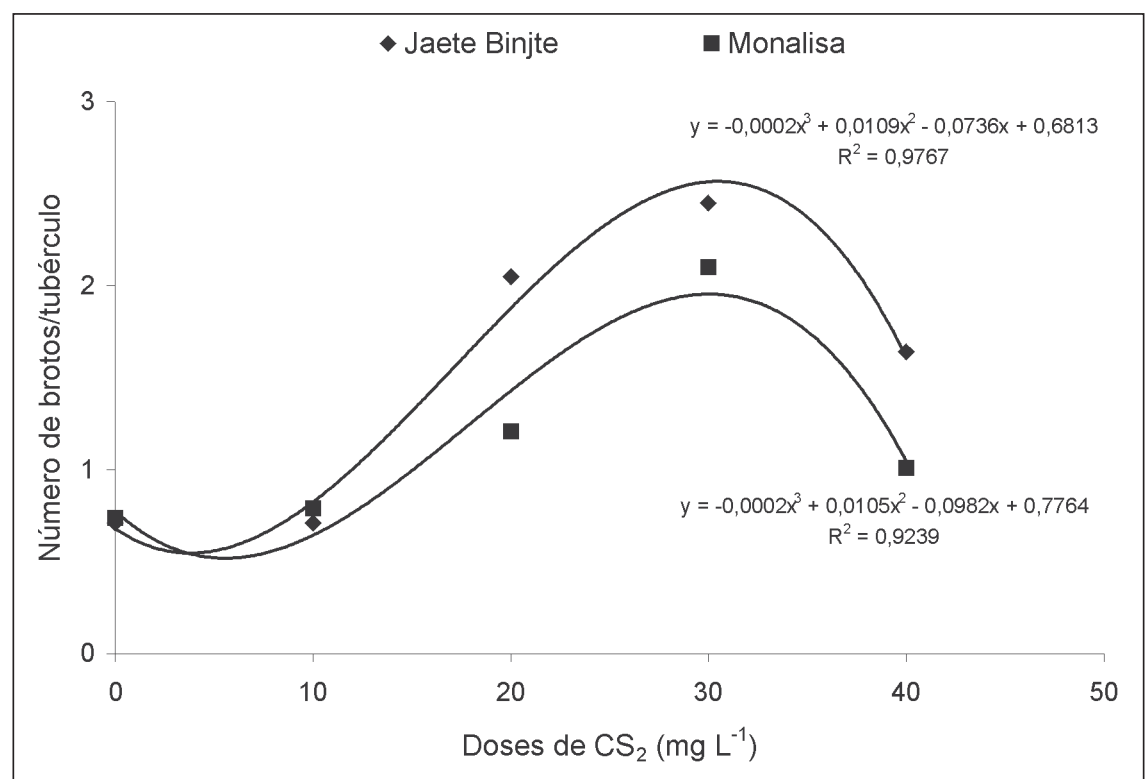

Figura 2. Comportamento da brotação de mini-tubérculos de batata das cultivares Jaete Bintje e Monalisa em relação às diferentes concentrações de $\mathrm{CS}_{2}$, aos 35 DAT. Botucatu, UNESP, 2002.

ferente à brotação foram verificados nas concentrações de 20 e $30 \mathrm{mg} \mathrm{L}^{-1}$, onde ambas as cultivares apresentaram nível máximo de brotação. Fato interessante foi observado para a dose de $40 \mathrm{mg} \mathrm{L}^{-1}$, que proporcionou números médios de brotos por tubérculo inferiores à concentração de $30 \mathrm{mg} \mathrm{L}^{-1}$. Isso se deve ao efeito fitotóxico do bissulfureto de carbono sobre as gemas, provocando a queima e, conseqüente, morte das mesmas.
Portanto, concentrações abaixo de 20 $\mathrm{mg} \mathrm{L}^{-1}$ e acima de $30 \mathrm{mg} \mathrm{L}^{-1}$ podem levar ao insucesso da quebra de dormência em tubérculos das cultivares Jaete Bintje e Monalisa.

Já as cultivares Ágata e Mondial demonstraram sensibilidade positiva (Tabela 1) para a concentração de $10 \mathrm{mg}$ $\mathrm{L}^{-1}$ de bissulfureto de carbono, o que não foi verificado nas outras cinco cultivares estudadas. Verifica-se através da Fi- 


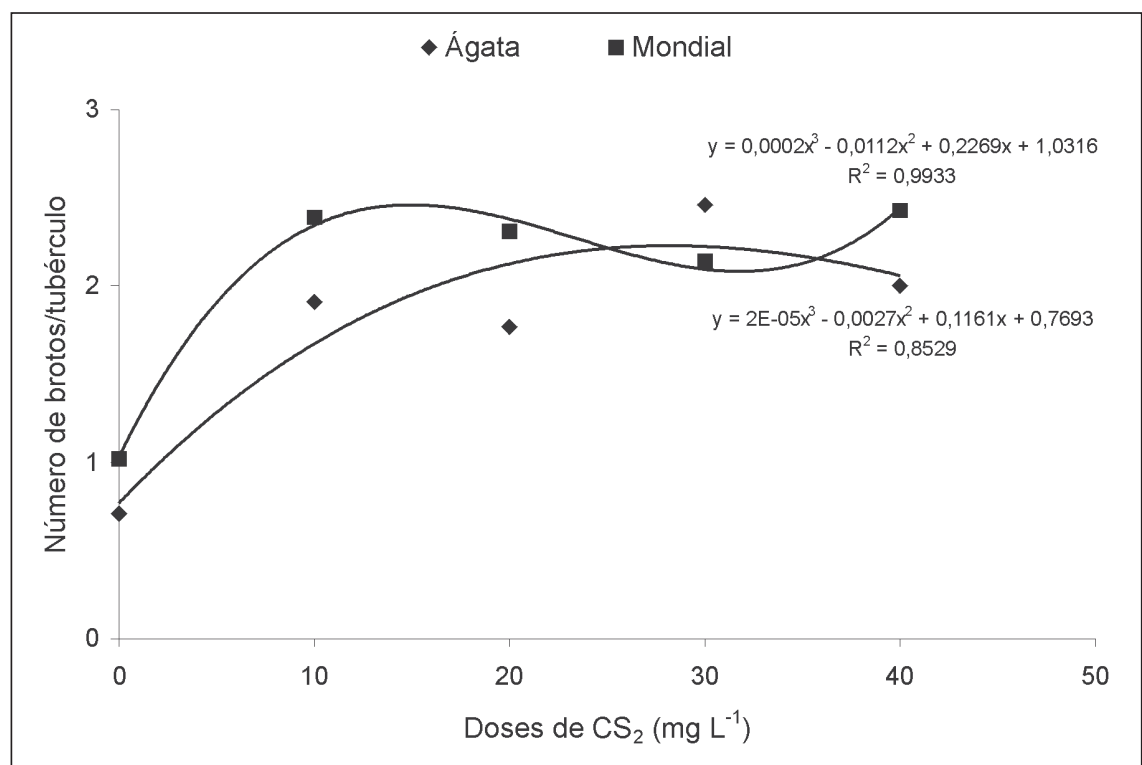

Figura 3. Comportamento da brotação de mini-tubérculos de batata das cultivares Ágata e Mondial em relação às diferentes concentrações de $\mathrm{CS}_{2}$, aos 35 DAT. Botucatu, UNESP, 2002.

gura 3 que os dados obtidos para as cultivares Ágata e Mondial se adequaram a um ajuste de equação cúbica. Ambas as cultivares apresentaram elevado número de brotos por tubérculos aos 35 DAT na concentração de $10 \mathrm{mg} \mathrm{L}^{-1}$. Concentrações superiores a $10 \mathrm{mg} \mathrm{L}^{-1}$, não causaram problemas de fitotoxicidade nos mini-tubérculos, sendo que o número médio de brotos por tubérculos permaneceu praticamente constante com o aumento da concentração. Esse comportamento deve-se ao fato das cultivares Ágata e Mondial apresentarem facilidades naturais de brotação das gemas, mesmo quando não são adotadas técnicas de quebra de dormência, sendo que tal facilidade de brotação está associada à concentração de açúcares no interior do tubérculo (Loon, 1983).

Deste modo, a correta utilização do bissulfureto de carbono, em concentrações apropriadas às diferentes cultivares, poderá levar à quebra de dormência e ao estímulo para a brotação de maior número de gemas em batata-semente. Isso possibilitará a formação de maior quantidade de ramos quando implantada a lavoura, fator este fundamental para a maior produção de fotoassimilados e, conseqüentemente, maior número e tamanho dos tubérculos comercialmente desejáveis.

\section{LITERATURA CITADA}

CASTRO, J.A. Forçamento da brotação em batata-semente. Tecnologia e produção de batata-semente: coletânea de artigos técnicos. Brasília: AGIPAN, 1976. 47 p.

BEUKEMA, H.P.; ZAAG, R.G. Potato improvement some factor and facts. Wageningen: International Agriculture Center, 1979. 222 p.

DANIELS, J. Efeitos da colheita antecipada e do forçamento da brotação na produtividade da batata no Rio Grande do Sul. Pelotas: EMBRAPAUEPAE, 1980. 4 p. (EMBRAPA - UEPAE, Comunicado Técnico, 10).

LOON, C.D. The effect of cold shock on dormancy of potatoes. Potato Research, v.26, n.1, p.61-84, 1983.

MEIJERS, C.P. Effect of carbon-dissulphid on the dormancy and sprouting of seed potatoes. Potato Research, v.15, n.2, p.1160-1165, 1972.

PÓGI, M.C.; BRINHOLI, O. Efeitos da maturidade, do peso da batata-semente e da quebra da dormência sobre a cultivar de batata (Solanum tuberosum L.), Itararé (IAC 59860). Pesquisa Agropecuária Brasileira, Brasília, v.30, n.11, p.1305-1311, 1995.

REGHIN, M.Y. Estudo do forçamento da brotação em batatas-semente (Solanum tuberosum L.). 1982. 132 p. (Tese mestrado), FCA, UNESP, Botucatu.

SCIVITTARO, A.; BOOCK, O.J. Experiências sobre ativação da brotação de batata-semente pelo bissulfureto de carbono. Bragantia, Campinas, v.22, p.19-25, 1963.

TIMM, H.; RAPPAPORT, L.; BISHOP, J.C. Sprouting plant growth and tuber production as affected by chemical treatment of with potato seed pieces. IV. Responses of dormant and sprouted seed tubers to gibberellic acid. American Potato Journal, v.39, n.3, p.107-115. 1962.

TOLEDO, F.F; MARCOS FILHO, J. Manual de sementes: tecnologia de produção. Campinas: Agronômica Ceres, 1977. 224 p. 